\title{
T-Shaped Compact Dielectric Resonator Antenna for UWB Application
}

\author{
Ahmed Zitouni ${ }^{1}$, Noureddine Boukli-Hacene ${ }^{2}$ \\ ${ }^{1}$ Laboratory of Telecommunications, Faculty of Science and Engineering, University Hassiba Benbouali of Chlef, Chlef, \\ Algeria \\ ${ }^{2}$ Laboratory of Telecommunications, Faculty of Technology, University of Tlemcen, Tlemcen, Algeria. \\ Email: ahmed_zitouni_71@yahoo.fr
}

\begin{abstract}
In this article, a novel T-shaped compact dielectric resonator antenna for ultra-wideband (UWB) application is presented and studied. The proposed DRA structure consists of Tshaped dielectric resonator fed by stepped microstrip monopole printed antenna, partial ground plane and an inverted L-shaped stub. The inverted L-shaped stub and parasitic strip are utilized to improve impedance bandwidth. A comprehensive parametric study is carried out using HFSS software to achieve the optimum antenna performance and optimize the bandwidth of the proposed antenna. From the simulation results, it is found that the proposed antenna structure operates over a frequency range of 3.45 to more than $28 \mathrm{GHz}$ with a fractional bandwidth over $156.12 \%$, which covers UWB application, and having better gain and radiation characteristics. The novelty of the work is using a slot in the ground plane, L-shaped tuning stub and a parasitic strip to enhancing impedance bandwidth. The proposed design can support wide application such as UWB communication systems, and Radar applications.
\end{abstract}

\section{Introduction}

Since the release of the frequency band from 3.1 to 10.6 $\mathrm{GHz}$ for commercial use by the Federal Communication (FCC) [1],Ultra wideband communication systems achieves immense attention in the wireless communication due to several advantages, including simple hardware configuration, high data transmission rates, high-precision ranging, low cost and low power consumption[2].

To overcome growing demand for wideband or multiband operation, various techniques have been reported over the years. In [3] a novel multiband planar patch antenna based on composite right/left-handed (CRLH) transmission-lines metamaterial (MTM) unit-cells have been proposed. In [4] the antenna is composed of back-to-back triangular shaped radiating patches that are excited through a common feedline, with truncated T-shaped ground-plane that is located under the feed-line. The antenna in [5] uses variants of monofilar Archimedean metamaterial-based unit-cells comprising spiral and rectangular configurations in the realization of a novel Leaky-wave antenna (LWA). In [6] the proposed antenna is shown to operate over a wideband from UHF to C-band with good radiation characteristics. In [7] a compact planar dipole antenna is proposed that employs three radiation elements to implement a multimode antenna that radiates energy omnidirectionally in its three frequency bands. The array antenna presented in [8] consists of 6X6 matrix of spiral-shaped radiating elements that are excited through proximity-coupled, single feed-line. The antenna structure in [9] consists of dual-port slot antenna that is constructed on a single layer of dielectric substrate and operates over a large frequency bandwidth with a peak gain and maximum radiation efficiency at its mid-band operational frequency.

Recently, the dielectric resonator antenna (DRA) have attracted a considerable amount of interest in UWB antenna due to several striking characteristics such as high radiation efficiency, light weight, compact antenna size, various excitation mechanisms, wide bandwidth, low dissipation, and no excitation of surface waves [10-14].

Significant efforts for the DRA have been reported to achieve wide bandwidth enhancements in the last two decades, such as special feeding mechanisms [15, 16], stacked DRs [17-19], various geometries of DRAs [20-26], conformal patch feeding $[27,28]$ and introduction of an air gap between the DRA [29].

In this paper, we proposed a new ultra-wideband dielectric resonator antenna with enhanced bandwidth and improved radiation pattern. By implementing a combination mechanism of a T-shaped RDR, a stepped monopole antenna with truncated ground plane, exciting microstrip feed line, an inverted L-shaped stub, and a slot on the ground plane, ultra-wide impendence bandwidth with stable radiation patterns are achieved. By this new combination the proposed UWB DRA can covers UWB frequency band, and entire $\mathrm{Ku}$ and $\mathrm{K}$-band. The analyses in this paper are performed using the commercial HFSS software.

Simulation results of return loss, gain and far field radiation patterns are presented and discussed to validate the usefulness of the proposed antenna structure for UWB applications.

\section{Configuration and antenna design}

The configuration of the proposed DRA is shown in Fig. 1. The antenna is consists of a T-shaped dielectric resonator 
and a stepped microstrip fed monopole antenna that is supported by an FR4 microwave substrate with size of $25 \times 25 \mathrm{~mm}^{2}$, thickness of $0.8 \mathrm{~mm}$ and dielectric constant of 4.4. The DR is made of Rogers RT/Duroid 6010 microwave dielectric material with a dielectric constant of 10.2 and a loss tangent of 0.003 . The feeding structure comprised of a $50 \Omega$ microstrip transformer with $\mathrm{W}_{\mathrm{f}}=1.6 \mathrm{~mm}$ width and $\mathrm{L}_{\mathrm{f}}=8 \mathrm{~mm}$ length and a stepped monopole antenna with lengths of $\mathrm{L}_{P 1}=4.3 \mathrm{~mm}, \mathrm{~L}_{\mathrm{P} 2}=2.5 \mathrm{~mm}$ and widths of $\mathrm{W}_{\mathrm{P} 1}=1 \mathrm{~mm}, \mathrm{~W}_{\mathrm{P} 2}=4.3 \mathrm{~mm}$. By adjusting the position of the step-shaped feeding underneath the DR $\left(\mathrm{L}_{3}\right)$, a good impedance matching with a significant coupling can be achieved. The partial ground plane with size of $25 \times 11.5$ $\mathrm{mm}^{2}$ is applied on the back side of the dielectric substrate.

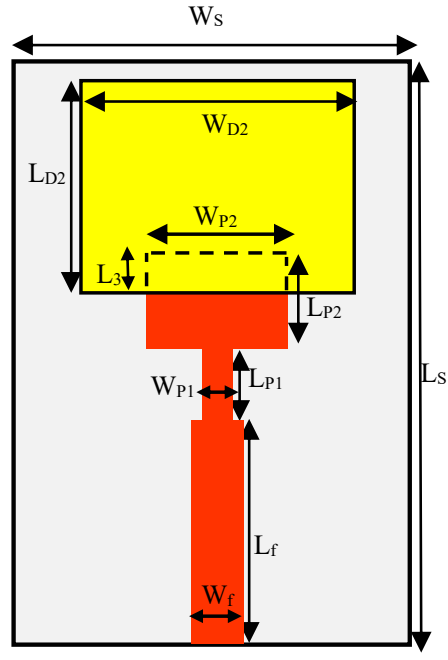

(a)

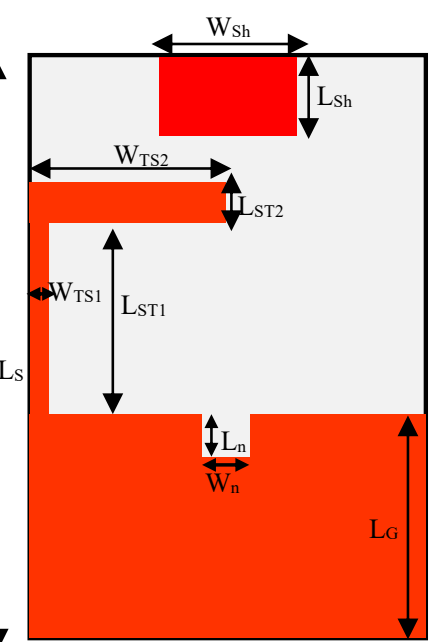

(b)

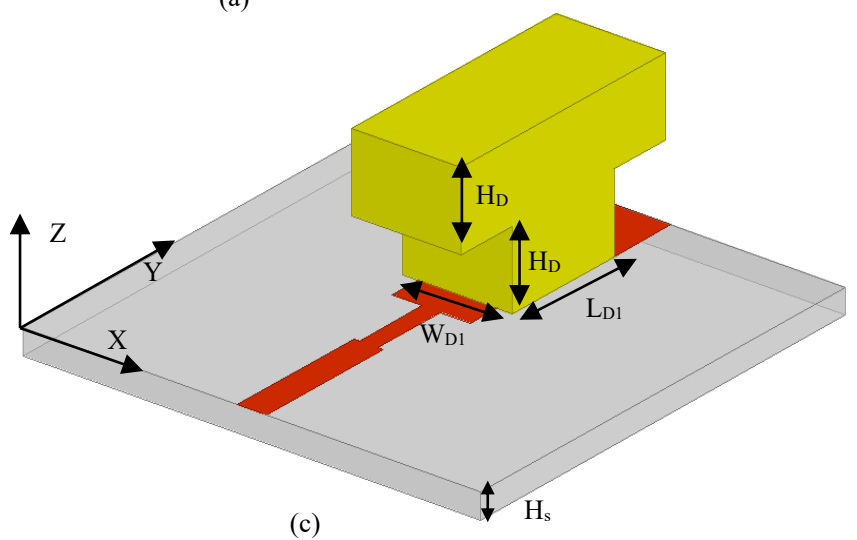

Figure 1: Geometry of the proposed UWB DRA (a) top view, (b) bottom view, and (c) 3-D view.

The design procedure of the proposed DRA is shown in Fig. 2.The simulated reflection coefficients for the different antenna structures shown in Fig. 2, are plotted in Fig. 3

From the Figure 3, we can see that the monopole antenna resonate at two frequencies with an impedance bandwidth from 8.8 to $23.8 \mathrm{GHz}$. In order to increase the bandwidth and move the lower band toward lower frequencies, a DR is loaded on the monopole as shown in Figure 2(b). From Figure 3, it can be seen that the monopole antenna loaded with the DR, achieves better impedance matching than the basic monopole antenna structure. But the antenna still presents some mismatches at low frequencies band (less than $5.2 \mathrm{GHz})$, the band $(18-19.4 \mathrm{GHz})$, and the high frequency band (more than $25.2 \mathrm{GHz}$ ). To further improve the impedance matching of the antenna, a slot is added to the partial ground plane, as shown in Figure 2(c). From Figure 3 , it is clear that the added slot can improve the impedance matching; however, the antenna still has a mismatch at the low frequency less than $5.2 \mathrm{GHz}$. So, to improve this impedance mismatching at low frequencies, an L-shaped tuning stub is added to truncated ground plane, as shown in Figure 2(d). We can notice from Figure 3 that the monopole antenna loaded with the DR and the added slot in the ground plane and added L-shaped tuning stub shows a better impedance matching than the previous structures.

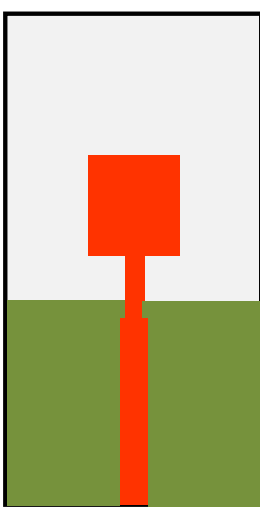

(a)

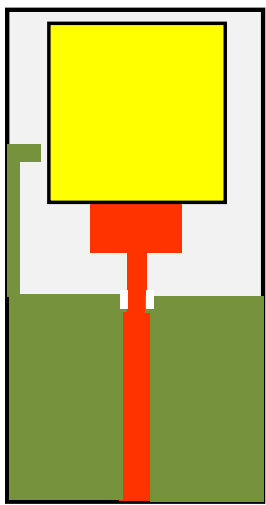

(d)

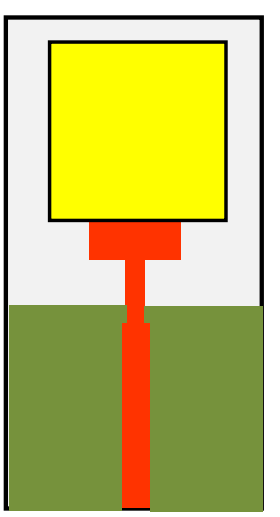

(b)

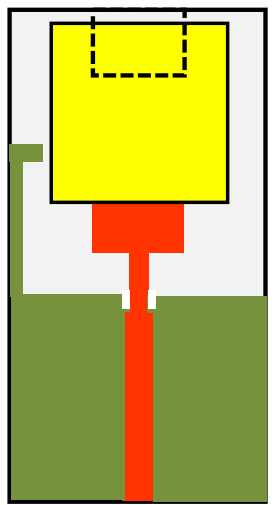

(e)

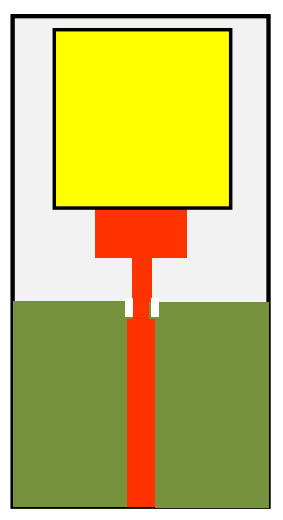

(c)
Figure 2: Evolution of the proposed UWB DRA. (a) Monopole antenna. (b) Monopole antenna loaded with the DR. (c) Monopole antenna loaded with the DR and the added slot in the ground plane. (d) Monopole antenna loaded with the DR and the added slot in the ground plane and added L-shaped tuning stub. (e) The proposed DRA.

To further improve the impedance matching and get a better reflection coefficient, a parasitic strip is added at the bottom of substrate, as shown in Figure 2(e).From Figure 3, we can notice that the proposed antenna has a better impedance matching over a very wide frequency band from $3.4 \mathrm{GHz}$ to more than $28 \mathrm{GHz}$, a bandwidth of more than $156.7 \%$; and a reflection coefficient that can reach until about $-45 \mathrm{~dB}$. 


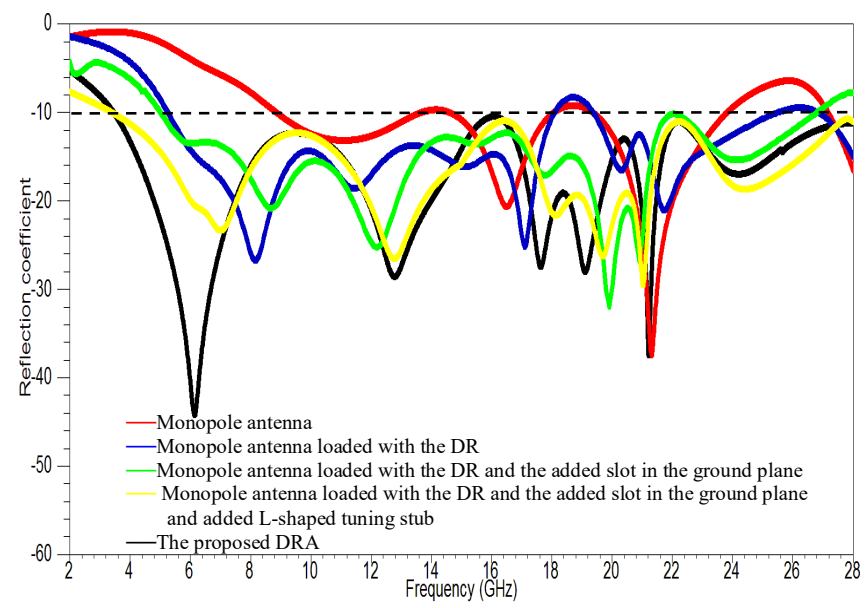

Figure 3: Simulated reflection coefficient for various antenna structures shown in Figure 2.

The proposed DRA was designed, simulated, and optimized using HFSS. The parameters of proposed DRA are as follows: $\mathrm{L}_{\mathrm{S}}=25 \mathrm{~mm}, \mathrm{~W}_{\mathrm{S}}=25 \mathrm{~mm}, \mathrm{H}_{\mathrm{S}}=0.8 \mathrm{~mm}, \mathrm{~L}_{\mathrm{D} 1}=7 \mathrm{~mm}$, $\mathrm{W}_{\mathrm{D} 1}=6 \mathrm{~mm}, \mathrm{~L}_{\mathrm{D} 2}=14 \mathrm{~mm}, \mathrm{~W}_{\mathrm{D} 2}=6 \mathrm{~mm}, \mathrm{H}_{\mathrm{D}}=2.5 \mathrm{~mm}, \mathrm{~L}_{\mathrm{f}}=8$ $\mathrm{mm}, \mathrm{W}_{\mathrm{f}}=1.6 \mathrm{~mm}, \mathrm{~L}_{\mathrm{P} 1}=4.3 \mathrm{~mm}, \mathrm{~W}_{\mathrm{P} 1}=1 \mathrm{~mm}, \mathrm{~L}_{\mathrm{P} 2}=2.5 \mathrm{~mm}$, $\mathrm{W}_{\mathrm{P} 2}=4.3 \mathrm{~mm}, \mathrm{~L}_{3}=0.7 \mathrm{~mm}, \mathrm{~L}_{\mathrm{G}}=11.5 \mathrm{~mm}, \mathrm{~L}_{\mathrm{n}}=1.5 \mathrm{~mm}$, $\mathrm{W}_{\mathrm{n}}=1.6 \mathrm{~mm}, \mathrm{~L}_{\mathrm{TS} 1}=6 \mathrm{~mm}, \mathrm{~W}_{\mathrm{TS} 1}=0.5 \mathrm{~mm}, \mathrm{~L}_{\mathrm{TS} 2}=1 \mathrm{~mm}$, $\mathrm{W}_{\mathrm{TS} 2}=6 \mathrm{~mm}, \mathrm{~L}_{\mathrm{sh}}=4 \mathrm{~mm}, \mathrm{~W}_{\mathrm{sh}}=4.3 \mathrm{~mm}$.

\section{Parametric study}

In order to accomplish an investigation of the characteristics of the DRA, to obtain the most effective antenna performance, a parametric study is achieved. The commercial software Ansof HFSS is used for the parametric analysis. Important parameters of the proposed DRA are investigated by changing each time a parameter while keeping other parameters unchanged.

The effect of the height of the DR on the reflection coefficients for the proposed DRA is illustrated in Figure 4.

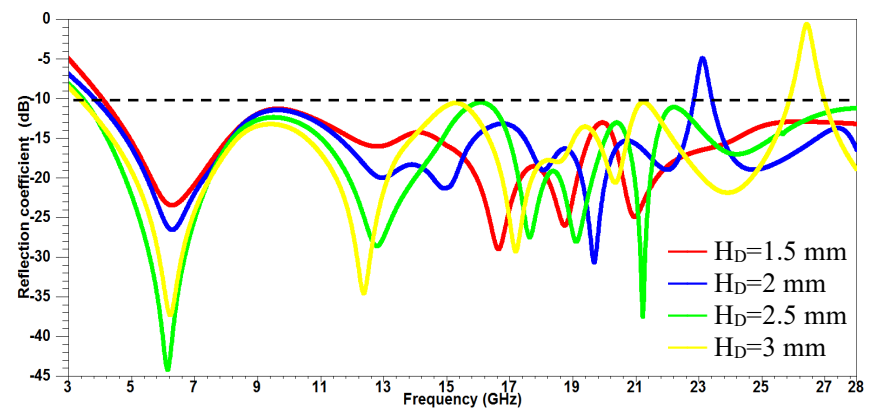

Figure 4: Simulated reflection coefficient for various height of DR.

It can be seen that, the height of ground plane has considerable effect on the reflection coefficient of the DRA at the high frequency bands; but at the low frequency band this effect is minor. As shown in Figure 4, for the proposed antenna, the best matching and bandwidth is achieved at $\mathrm{H}_{\mathrm{D}}=2.5 \mathrm{~mm}$. The Figure 5 illustrates the influence of the tuning stub length LST1. It is observed that by increasing lengths of LsT1, impedance bandwidth is sensibly degraded, at the low frequency band. Thus, form this figure the optimized value of LST1 is equal to $6 \mathrm{~mm}$. The effect of various lengths of $\mathrm{W}_{\mathrm{ST} 2}$ on reflection coefficient versus frequency is illustrated in Figure 6. It can be seen that by changing the length of $\mathrm{W}_{\mathrm{ST} 2}$, the impedance matching of the antenna will be changed, especially at the low frequency band. From Figure 6, the optimized value is $\mathrm{W}_{\mathrm{ST} 2}=6 \mathrm{~mm}$. Figure 7 shows the effect of the partial ground plane length, $\mathrm{L}_{\mathrm{G}}$ on the reflection coefficient of the proposed DRA. From this figure, it can be seen that, the length of the ground plane has a very important effect on the bandwidth and the impedance matching of the antenna. The best matching and impedance bandwidth is achieved at $\mathrm{L}_{\mathrm{G}}=11.5 \mathrm{~mm}$.

The last parameter to be examined which plays a fundamental role in the excitation of the DR is the length $\mathrm{L}_{3}$.

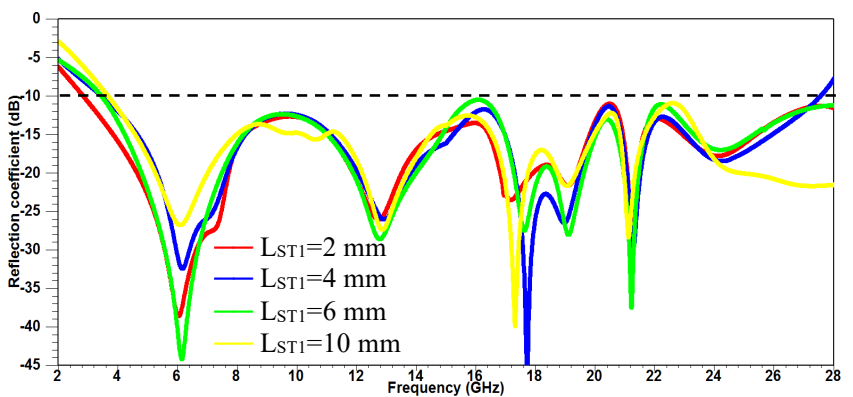

Figure 5: Simulated reflection coefficient for various length of LsT1.

The effect of the length, $\mathrm{L}_{3}$ on the reflection coefficient of the proposed DRA is depicted in Figure 8. From this figure it is very clear that this parameter influences both the impedance matching and bandwidth of the proposed DRA. As a result, the best impedance matching is achieved at $\mathrm{L}_{3}=0.7 \mathrm{~mm}$.

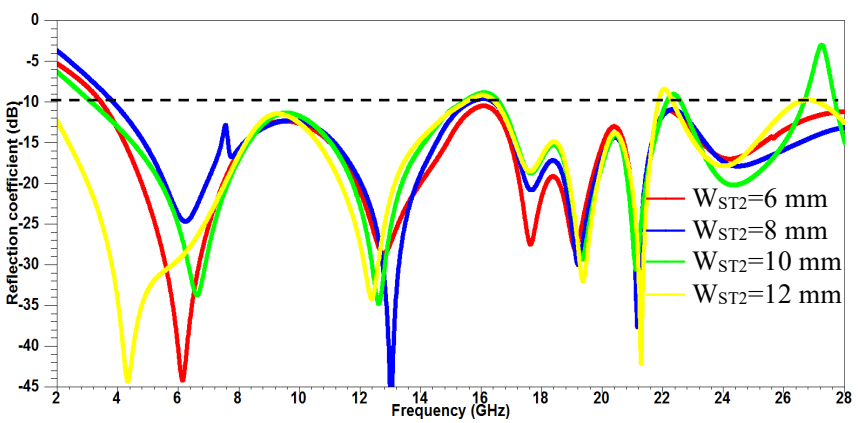

Figure 6: Simulated reflection coefficient for various length of WsT2.

\section{Results and discussions}

To validate the analysis of proposed antenna, the simulations were performed by using two commercial electromagnetic simulators: Ansoft HFSS and CST Microwave Studio. The optimized DRA parameters are: $\mathrm{Ls}_{\mathrm{S}}=25 \mathrm{~mm}, \mathrm{~W}_{\mathrm{s}}=25 \mathrm{~mm}$, $\mathrm{H}_{\mathrm{S}}=0.8 \mathrm{~mm}, \mathrm{~L}_{\mathrm{D} 1}=7 \mathrm{~mm}, \mathrm{~W}_{\mathrm{D} 1}=6 \mathrm{~mm}, \mathrm{~L}_{\mathrm{D} 2}=14 \mathrm{~mm}, \mathrm{~W}_{\mathrm{D} 2}=6$ $\mathrm{mm}, \mathrm{H}_{\mathrm{D}}=2.5 \mathrm{~mm}, \mathrm{~L}_{\mathrm{f}}=8 \mathrm{~mm}, \mathrm{~W}_{\mathrm{f}}=1.6 \mathrm{~mm}, \mathrm{~L}_{\mathrm{P} 1}=4.3 \mathrm{~mm}$, 
$\mathrm{W}_{\mathrm{P} 1}=1 \mathrm{~mm}, \mathrm{~L}_{\mathrm{P} 2}=2.5 \mathrm{~mm}, \mathrm{~W}_{\mathrm{P} 2}=4.3 \mathrm{~mm}, \mathrm{~L}_{3}=0.7 \mathrm{~mm}$, $\mathrm{L}_{\mathrm{G}}=11.5 \mathrm{~mm}, \mathrm{~L}_{\mathrm{n}}=1.5 \mathrm{~mm}, \mathrm{~W}_{\mathrm{n}}=1.6 \mathrm{~mm}, \mathrm{~L}_{\mathrm{TS} 1}=6 \mathrm{~mm}$, $\mathrm{W}_{\mathrm{TS} 1}=0.5 \mathrm{~mm}, \mathrm{~L}_{\mathrm{TS} 2}=1 \mathrm{~mm}, \mathrm{~W}_{\mathrm{TS} 2}=6 \mathrm{~mm}, \mathrm{~L}_{\mathrm{sh}}=4 \mathrm{~mm}$, $\mathrm{W}_{\mathrm{sh}}=4.3 \mathrm{~mm}$. The simulated reflection coefficient of proposed antenna is shown in Figure 9. From this figure, it can be seen that the simulated impedance bandwidth with HFSS for the UWB DRA is from 3.45 to more than $28 \mathrm{GHz}$ for return loss below $-10 \mathrm{~dB}$; on the other hand the simulated impedance bandwidth with CST is from 4.54 to 27.10 GHZ. The discrepancy between the results simulated by CST and HFSS is due to the different numerical techniques employed by both software, and also the accuracy of the simulation due to the wide range of simulation frequencies.

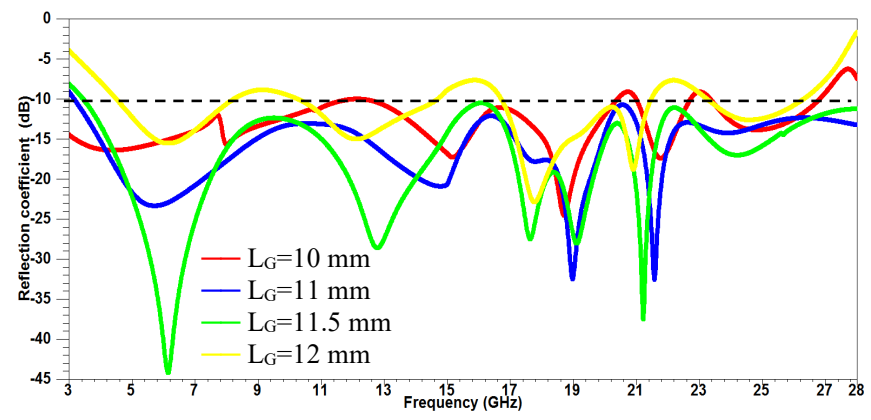

Figure 7: Simulated reflection coefficient for various length of partial ground plane, $\mathrm{L}_{\mathrm{G}}$.

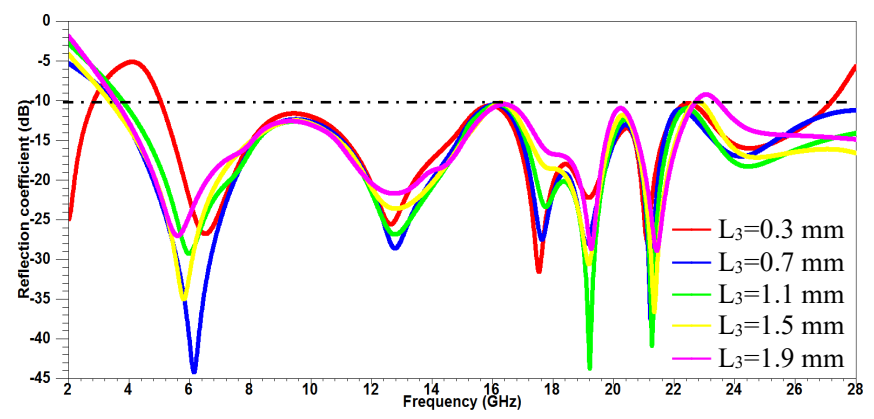

Figure 8: Simulated reflection coefficient for various length of $\mathrm{L}_{3}$.

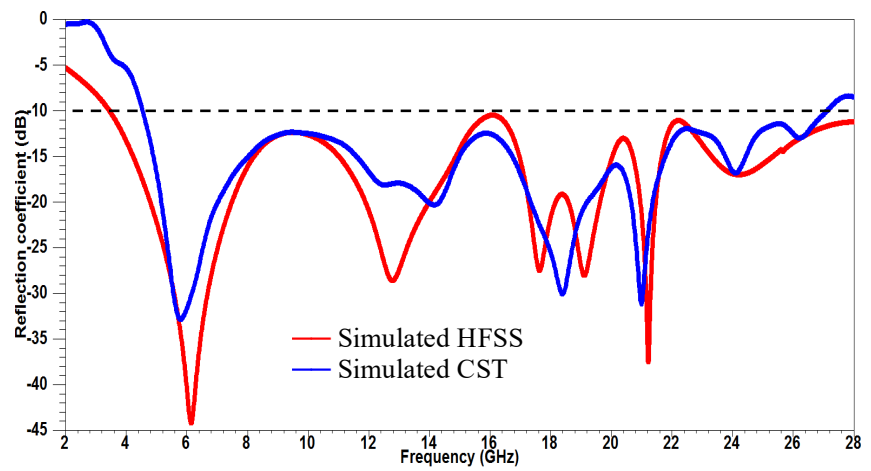

Figure 9: Simulated reflection coefficient of proposed DRA

The simulated radiation patterns in the $\mathrm{E}(y z)$-plane and $\mathrm{H}(x z)$-plane at four different frequencies $(5,10,16$, and 24
$\mathrm{GHz}$ ) are shown in Figure 10. From this figure, It can be seen that, in $x z$-plane (H-plane) the radiation patterns are practically symmetrical across the operating frequency range. However, in $y z$-plane (E-plane), the radiation patterns are not symmetrical and have some deformation at higher frequencies. This deformation is principally due to the effects of the higher order modes and the asymmetry of the structure.

Figure 11 illustrates the simulated peak gains of the proposed antenna. It is seen that the peak gain of the proposed antenna is nearly constant in the entire operating frequency range. However, the peak gain decreases in the frequency band $3-5 \mathrm{GHz}$.

The simulated group delay of the proposed antenna is shown in Figure 12. It can be seen that, the simulated group delay is almost constant and less than 1 ns which show good linearity within the UWB frequency range.

The simulated total efficiency versus frequency of proposed UWB DRA is illustrated in Figure 13. From the results it is noticed that the proposed UWB DRA provides high total efficiency within most operating frequency band. The highest radiation efficiency $(\sim 90 \%)$ is obtained at $5.3 \mathrm{GHz}$.

\section{Conclusions}

\section{Comparison with other structures}

To demonstrate the validity of the proposed UWB DRA, a comparison with the some existing designs in the literature is carried out in Table 1.

The summarized data in Table 1 reveals that the proposed UWB DRA achieved better operating bandwidth and percentage bandwidth compared other designs. It can also be observed from Table 1, the proposed antenna exhibits the highest gain and efficiency. However, its relatively big size compared to other designs, because in our design the antenna uses a DR while the others use only planar antennas. The comparison clearly confirms that the proposed UWB DRA is competitive when compared with other designs, and is great candidate for ultra-wideband communication systems.

\section{Conclusions}

In this paper, a new T-shaped compact dielectric resonator antenna for ultra wideband applications has been proposed and investigated. By feeding the DR with a stepped printed monopole antenna and using L-shaped tuning stub, a slot in the partial ground plane and a parasitic strip added at the bottom of substrate, an UWB DRA with increased bandwidth is achieved, with an impedance bandwidth from 3.45 to more than $28 \mathrm{GHz}$, covering more than $156.12 \%$. By using this new process which consists of L-shaped tuning stub, a slot in the partial ground plane and a parasitic strip, the proposed antenna is able to cover UWB frequency band, $\mathrm{Ku}$-band and $\mathrm{K}$-band. In addition, this antenna also provides an acceptable radiation pattern, stable peak gain and a nearly constant group delay in the operating bandwidth. Therefore, the proposed antenna is cost effective, simple and compact which make the antenna a good contender suitable for applications in various UWB systems. The proposed antenna 
supports the application in the field of UWB communication systems, and Radar applications.
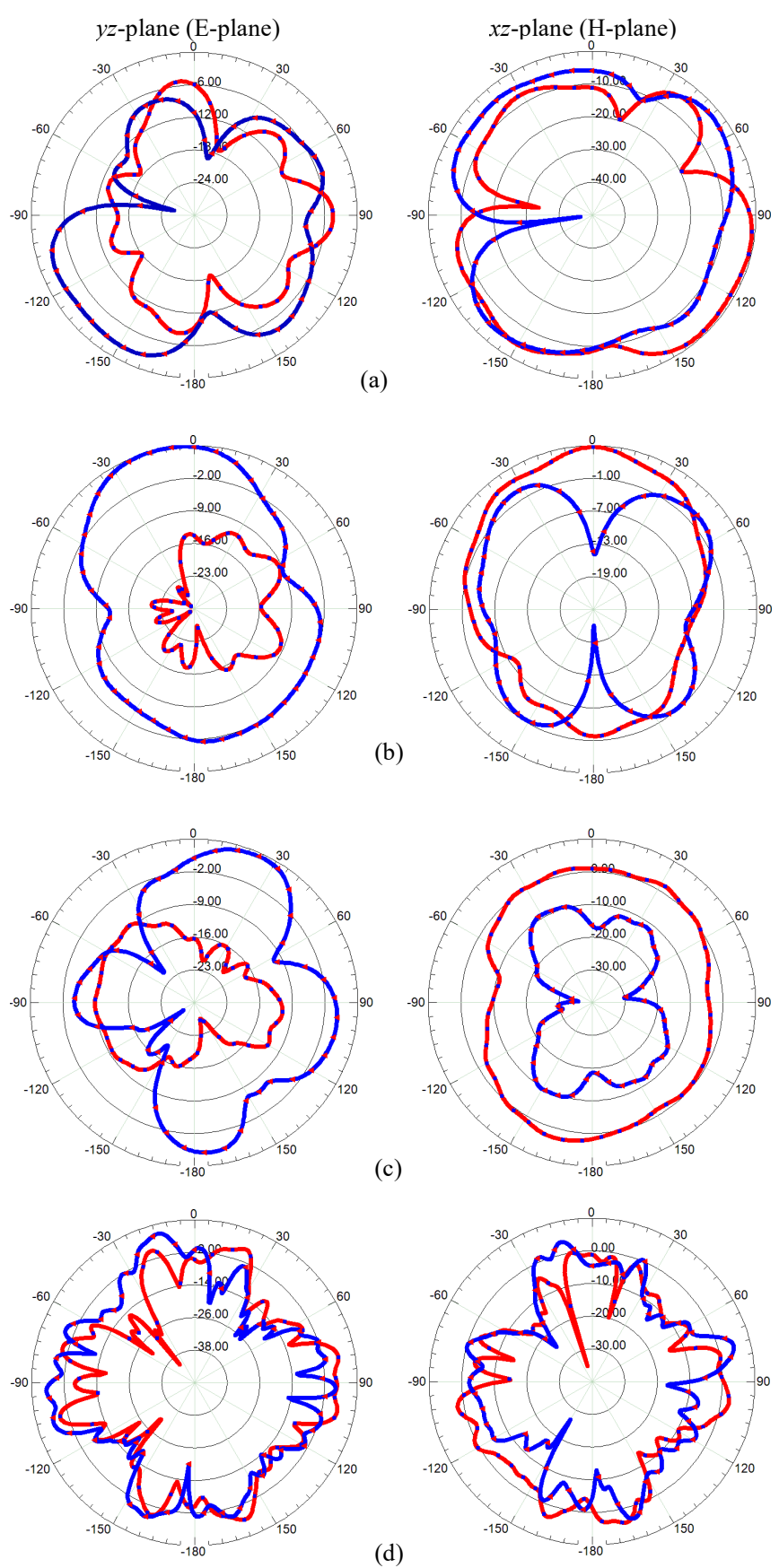

(d)

$$
\begin{aligned}
& \text { - Co-polar } \\
& -0 \text { Cross-polar }
\end{aligned}
$$

Figure 10: Simulated radiation patterns at frequencies (a) 5 , (b) 10, (c) 16, and (d) $24 \mathrm{GHz}$.

\section{Acknowledgements}

The authors would like to express their sincere thanks to all members of the laboratory of Telecommunications, University of Tlemcen and all the member of the of Electronics Department University of Chlef of the support of the research.

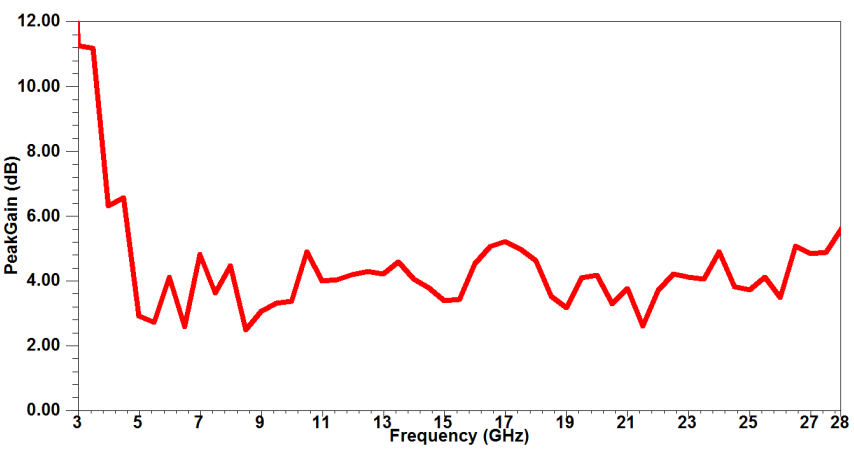

Figure 11: Simulated peak gain of proposed DRA

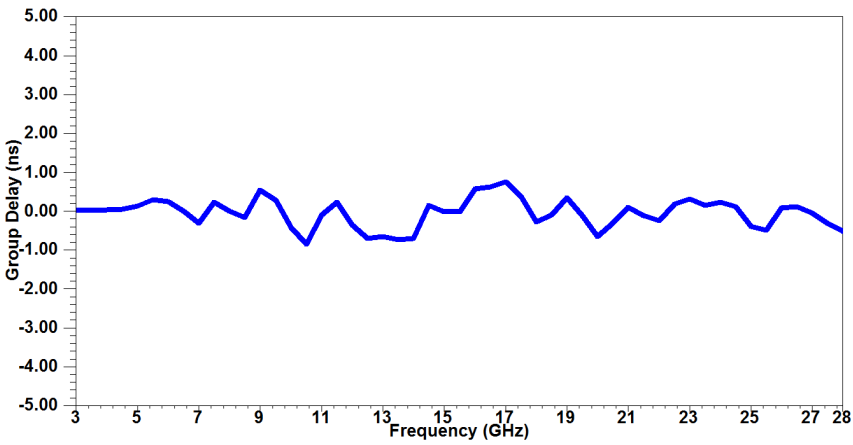

Figure 12: Simulated group delay of proposed DRA

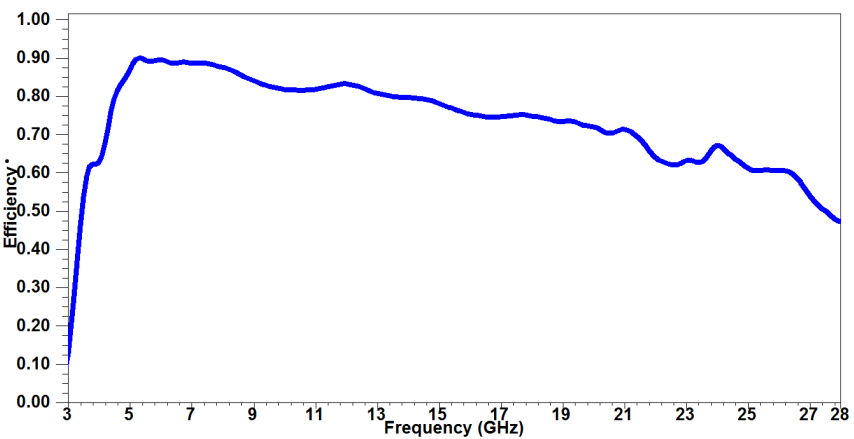

Figure 13: Simulated total efficiency of proposed DRA

Table 1: Comparison between the proposed antenna and

\begin{tabular}{|c|c|c|c|c|}
\hline Ref & $\begin{array}{c}\text { Volume } \\
{\left[\mathrm{mm}^{3}\right]}\end{array}$ & $\begin{array}{c}\text { Bandwidth } \\
{[\mathrm{GHz}]}\end{array}$ & $\begin{array}{l}\text { Max. } \\
\text { Gain } \\
{[\mathrm{dBi}]}\end{array}$ & $\begin{array}{c}\text { Max. } \\
\text { Eff } \\
{[\%]}\end{array}$ \\
\hline [30] & 73.44 & $\begin{array}{c}4.3-18.6 \\
(124.89 \%)\end{array}$ & 6.03 & 57.57 \\
\hline [31] & 104.86 & $\begin{array}{l}0.35-11.45 \\
(188.13 \%)\end{array}$ & 6.1 & 76 \\
\hline [32] & 85.56 & $\begin{array}{c}1.1-6.85 \\
(144.65 \%)\end{array}$ & 7.1 & 91 \\
\hline [33] & 427.68 & $\begin{array}{c}0.7-8 \\
(167.81 \%)\end{array}$ & 4 & 80 \\
\hline [34] & 516 & $\begin{array}{c}1.60-8.65 \\
(137.56 \%)\end{array}$ & 4.35 & 84 \\
\hline [35] & 600 & $\begin{array}{c}0.5-9.45 \\
(179.89 \%)\end{array}$ & 3.5 & 70 \\
\hline $\begin{array}{c}\text { Proposed } \\
\text { antenna }\end{array}$ & 3625 & $\begin{array}{c}3.45-28 \\
(156.12 \%)\end{array}$ & 5.2 & 90 \\
\hline
\end{tabular}




\section{References}

[1] First Report and Order in the matter of Revision of Part 15 of the Commission's Rules Regarding Ultra-Wideband Transmission Systems, Released by Federal Communications Commission ET-Docket 98-153, Apr. 22, 2002.

[2] E. G. Lim, Z. Wang, C.-U. Lei, Y. Wang, and K. Man, Ultra wideband antennas - Past and present, IAENG Int. J. Comput. Sci., vol. 37, pp.304-314, 2010.

[3] Mohammad Alibakhshikenari, Bal S. Virdee, Abdul Ali, Ernesto Limiti, Miniaturized Planar-Patch Antenna Based on Metamaterial L-shaped Unit-Cells for Broadband Portable Microwave Devices and Multiband Wireless Communication Systems, IET Microwaves, Antennas \& Propagation, Volume 12, Issue 7, 13 June 2018, p. 1080 - 1086.

[4] Mohammad Alibakhshikenari, Bal S. Virdee, Chan Hwang See, Raed Abd-Alhameed, Abdul Ali, Francisco Falcone, Ernesto Limiti, Wideband Printed Monopole Antenna for Application in Wireless Communication Systems, IET Microwaves, Antennas \& Propagation, Volume 12, Issue 7, 13 June 2018, p. 1222 - 1230.

[5] Mohammad Alibakhshikenari, Bal S. Virdee, Abdul Ali1, Ernesto Limiti, A novel monofilar-Archimedean metamaterial inspired leaky-wave antenna for scanning application for passive radar systems, Microw Opt Technol Lett. 2018; 60:2055-2060. https://doi.org/10. 1002/mop.31300.

[6] Mohammad Alibakhshikenari, Bal S. Virdee, Abdul Ali, and Ernesto Limiti, Extended Aperture Miniature Antenna Based on CRLH Metamaterials for Wireless Communication Systems Operating Over UHF to C-Band, Radio Science, Volume 53, Issue 2, February 2018, Pages 154-165, DOI: 10.1002/2017RS006515.

[7] Mohammad Alibakhshikenari, Bal S. Virdee, Ernesto Limiti, Triple-band planar dipole antenna for omnidirectional radiation, Microw Opt Technol Lett. 2018; 60: 1048-1051. https://doi.org/10.1002/mop.31098

[8] Mohammad Alibakhshikenari, Bal Singh Virdee and Ernesto Limiti, Wideband Planar Array Antenna Based on SCRLH-TL for Airborne Synthetic Aperture Radar Application, Journal of Electromagnetic Waves and Applications (TEWA), Volume 32, Issue 12, June 2018, Pages 1586-1599, DOI: 10.1080/09205071.2018.1460280

[9] Mohammad Alibakhshikenari, Mohsen Khalily, Bal Singh Virdee, Abdul Ali, Panchamkumar Shukla, Chan Hwang See, Raed A. Abd-Alhameed, Francisco J. Falcone, and Ernesto Limiti, Double-Port Slotted-Antenna with Multiple Miniaturized Radiators for Wideband Wireless Communication Systems and Portable Devices, Progress In Electromagnetics Research C, Vol. 90, 1-13, 2019.

[10] Y. Ge, K. Esselle, and T. Bird, Compact dielectric resonator antennas with ultrawide $60 \%-110 \%$ bandwidth, IEEE Transactions on Antennas and Propagation, vol. 59, no. 9, pp. 3445-3448, Sept. 2011.

[11]K.S. Ryu; A.A. Kishk, UWB Dielectric Resonator Antenna Having Consistent Omnidirectional Pattern and Low Cross-Polarization Characteristics, IEEE Transactions on Antennas and Propagation, vol.59, no.4, pp.1403-1408, April 2011.

[12] M. Abedian, S.K.A. Rahim; S. Danesh, Design of a Compact UWB Rectangular Dielectric Resonator Antenna Using a Simple Structure, In 8th European
Conference on Antennas and Propagation (EuCAP), pp. 2904-2907, April 2014.

[13] Longfang Zou, C. Fumeaux, A Cross-Shaped Dielectric Resonator Antenna for Multifunction and Polarization Diversity Applications, IEEE Antennas and Wireless Propagation Letters, vol.10, no., pp.742-745, 2011.

[14] Danesh, S.; Rahim, S.K.A.; Abedian, M.; Khalily, M.; Hamid, M.R., Frequency-Reconfigurable Rectangular Dielectric Resonator Antenna, IEEE Antennas and Wireless Propagation Letters, vol.12, no., pp.13311334, 2013.

[15] Chang, W.; Feng, Z., Investigation of a novel wideband feeding technique for dielectric ring resonator antennas, IEEE Antennas Wirel. Propag. Lett., 8 (2009), 348-351.

[16] Denidni, T.; Weng, Z., Hybrid ultra-wideband dielectric resonator antenna and band-notched designs, IET Microw. Antennas Propag., 5 (2011), 450-458.

[17] Shum, S.M.; Luk, K.M. Stacked annular-ring dielectric resonator antenna excited by axi-symmetric coaxial probe, IEEE Trans. Antennas Propag., 43 (1995), 889892.

[18] Wlash, A.G.; Young, S.D., Long, S.A.: An investigation of stacked and embedded cylindrical dielectric resonator antenna, IEEE Antennas Wirel. Propag. Lett., 5 (2006), $130-133$.

[19]Denidni, T.A.; Rao, Q.J., Sebak, A.R.: Broadband Lshaped dielectric resonator antenna, IEEE Antennas Wirel. Propag. Lett., 4 (2005), 453-454.

[20]A. A. Kishk, Y. Yin, and A. W. Glisson, Conical dielectric resonator antennas for wideband applications, IEEE Trans. Antennas Propag., vol. 50, pp. 469-474, Apr. 2002.

[21]A. A. Kishk, Elliptic dielectric resonator antenna for circular polarization with single feed, Microw. Opt. Technol. Lett., vol. 37, no. 6, pp. 454-456, Jun. 2003.

[22]P. V. Vijumon, S. K. Menon, M. N. Suma, B. Lehakumari, M. T. Sebastian, and P. Mohanan, Broadband elliptical dielectric resonator antenna, Microw. Opt. Technol. Lett., vol. 48, no. 1, pp. 65-67, Jan. 2006.

[23] A. A. Kishk, Wideband dielectric resonator antenna in a truncated tetrahedron form excited by a coaxial probe, IEEE Trans. Antennas Propag., vol. 51, no. 10, pp. 2907-2912, Oct. 2003.

[24] T.-H. Chang and J.-F. Kiang, Broadband dielectric resonator antenna with an offset well, IEEE Antennas Wireless Propag. Lett., vol. 6, pp. 564-567, 2007.

[25] R. Chair,A.A. Kishk, and K.-F. Lee, Wideband stairshaped dielectric resonator antennas, IET Microw., Antennas Propag., vol. 1, no. 2, pp. 299-305, Apr. 2007.

[26]X. L. Liang and T. A. Denidni, H-shaped dielectric resonator antenna for wideband applications, IEEE AntennasWireless Propag. Lett., vol. 7, pp. 163-166, 2008.

[27]Zhang, L.N.; Zhong, S.S.; Liang, X.L., Wideband Ushaped dielectric resonator antenna fed by triangle patch, Microw. Opt. Technol. Lett., 52 (2010), 24352438.

[28] Gao, Y.; Feng, Z.; Zhang, L., Compact asymmetrical Tshaped dielectric resonator antenna for broadband 
applications, IEEE Trans. Antennas Propag., 60 (2012), $1611-1615$.

[29] G. P. Junker, A. A. Kishk, A. W. Glisson, and D. Kajfez, Effect of an air gap on a cylindrical dielectric resonator antennas operating in the TM01 mode, Electron. Lett., vol. 30, no. 2, pp. 97-98, 1994.

[30] Mohammad Alibakhshi Kenari, Design and Modeling of New UWB Metamaterial Planar Cavity Antennas with Shrinking of the Physical Size for Modern Transceivers, International Journal of Antennas and Propagation, vol. 2013, Article ID 562538, 12 pages, 2013. doi: $10.1155 / 2013 / 562538$.

[31] Mohammad Alibakhshi-Kenari, Mohammad NaserMoghadasi, Novel UWB Miniaturized Integrated Antenna Based on CRLH Metamaterial Transmission Lines, AEUE Elsevier- International Journal of Electronics and Communications, Volume 69, Issue 8, August 2015, Pages 1143-1149.

[32] Mohammad Alibakhshi-Kenari, Mohammad NaserMoghadasi, Ramazan Ali Sadeghzadeh, Bal Singh Virdee, Metamaterial-Based Antennas for Integration in UWB Transceivers and Portable Microwave Handsets, International Journal of $R F$ and Microwave ComputerAided Engineering, Volume 26, Issue 1, January 2016, pages: 88-96.

[33] Mohammad Alibakhshi-Kenari, Mohammad NaserMoghadasi, Ramazan Ali Sadeghzadeh, Bal Singh Virdee, Ernesto Limiti, New Compact Antenna Based on Simplified CRLH-TL for UWB Wireless Communication Systems, International Journal of $R F$ and Microwave Computer-Aided Engineering, Volume 26, Issue 3, March 2016, pages: 217-225.

[34] Mohammad Alibakhshikenari, Bal Singh Virdee, and Ernesto Limiti, Compact Single Layer Travelling-Wave Antenna Design Using Metamaterial TransmissionLines, Radio Science, Volume 52, Issue 12 December 2017, Pages 1510-1521, DOI: 10.1002/2017RS006313.

[35]Ramazan Ali Sadeghzadeh, Mohammad AlibakhshiKenari, and Mohammad Naser-Moghadasi, UWB Antenna Based on SCRLH-TLs for Portable Wireless Devices, Microwave and Optical Technology Letters, Volume 58, Issue 1, January 2016, Pages: 69-71. 